\title{
Note from the Publisher
}

It is our pleasure to present the latest changes implemented in Revue de Métallurgie in order to improve its international visibility.

First of all, the journal is now hosted and distributed by our partner, Cambridge University Press. This cooperation will maximize the dissemination of original research results published in Revue de Métallurgie through Cambridge's global footprint.

Secondly, we encourage the authors to submit their papers preferably in English (although we continue to accept articles in French) and, for papers written in English, the title, abstract and keywords in French will no longer be necessary.

We are sure that the use of the English language will help to increase the international audience of the journal. Thus, our goal, with the editorial board of Revue de Métallurgie, is to make the journal even more recognized worldwide as a high-quality publication in metallurgy. The following steps to move in this direction will be to update and expand the aims and scope and, for 2013, to change the title to an English title.

Thanks to our authors and readers for their support for Revue de Métallurgie.

Agnès Henri

Managing Editor 